\title{
Resina Draconis Reduces Acute Liver Injury and Promotes Liver Regeneration after 2/3 Partial Hepatectomy in Mice
}

\author{
Zhi-yong He, ${ }^{1,2}$ Kai-han Lou, ${ }^{1}$ Jia-hui Zhao, ${ }^{1}$ Ming Zhang, ${ }^{1}$ Lan-chun Zhang, ${ }^{3}$ Ju Li, ${ }^{4}$ \\ Hao-fei Yu, ${ }^{3}$ Rong-ping Zhang $\mathbb{D},^{3,4}$ and Hu Wei-yan $\mathbb{D}^{1,2,3}$ \\ ${ }^{1}$ The Key Laboratory of Stem Cell and Regenerative Medicine, Institute of Molecular and Clinical Medicine, \\ Kunming Medical University, Kunming 650500, China \\ ${ }^{2}$ Monash Immune Regeneration and Neuroscience Laboratories, Department of Anatomy and Developmental Biology, \\ Monash University, Clayton, Melbourne 3800, Australia \\ ${ }^{3}$ School of Pharmaceutical Science \& Yunnan Key Laboratory of Pharmacology for Natural Products, \\ Kunming Medical University, Kunming 650500, China \\ ${ }^{4}$ Yunnan University of Chinese Medicine, Kunming 650500, China \\ Correspondence should be addressed to Rong-ping Zhang; zhrpkm@163.com and Hu Wei-yan; huweiyan2004@163.com
}

Received 25 June 2020; Revised 17 August 2020; Accepted 7 September 2020; Published 7 October 2020

Academic Editor: Hongwei Zhang

Copyright (C) 2020 Zhi-yong He et al. This is an open access article distributed under the Creative Commons Attribution License, which permits unrestricted use, distribution, and reproduction in any medium, provided the original work is properly cited.

\begin{abstract}
Aim. To investigate the protective effects and possible mechanisms of action of resina draconis (RD) on acute liver injury and liver regeneration after 2/3 partial hepatectomy $(\mathrm{PH})$ in mice. Methods. 2/3 $\mathrm{PH}$ was used to induce acute liver injury. Mice were divided into three groups: sham, vehicle $+2 / 3 \mathrm{PH}$, and $\mathrm{RD}+2 / 3 \mathrm{PH}$. Resina draconis was administered intragastrically after $2 / 3 \mathrm{PH}$ into the $\mathrm{RD}+2 / 3 \mathrm{PH}$ group, and the same volume of vehicle (1\% sodium carboxymethyl cellulose) was injected into the vehicle $+2 / 3$ $\mathrm{PH}$ group and sham group mice. The index of liver to body weight (ILBW) and proliferating cell nuclear antigen (PCNA) were assayed to evaluate liver regeneration. Blood and liver tissues were collected for serological and western blotting analysis. Results. Resina draconis protected against 2/3 $\mathrm{PH}$-induced acute severe liver injury and promoted liver regeneration as shown by significantly increased ILBW compared with that of controls. $2 / 3 \mathrm{PH}$ increased serum AST and ALT levels, which were significantly decreased by RD treatment, while $2 / 3 \mathrm{PH}$ decreased serum TP and ALB, which were increased by RD treatment. In the $\mathrm{RD}+2 / 3 \mathrm{PH}$ group, PCNA expression was significantly increased compared with the $2 / 3 \mathrm{PH}$ group. Further, hepatocyte growth factor (HGF), TNF $\alpha$, and EGFR levels were increased in the RD group at postoperative days 2 and 4 compared with the those in the $2 / 3 \mathrm{PH}$ group. Conclusion. Our results suggest that RD ameliorates acute hepatic injury and promotes liver cell proliferation, liver weight restoration, and liver function after $2 / 3 \mathrm{PH}$, probably via HGF, TNF $\alpha$, and EGFR signaling.
\end{abstract}

\section{Introduction}

The liver plays a central role in detoxification and protein synthesis and produces digestive biochemicals. It also possesses the unique ability to regenerate after surgical resection or injury to maintain these essential functions [1-4]. The clinical application of partial hepatectomy $(\mathrm{PH})$ or living donor liver transplantation (LDLT) for the treatment of primary or metastatic liver tumors and end-stage liver disease depends on effective liver regeneration [5-7]. Optimizing liver regeneration would have great clinical potential in improving outcomes from liver disease. Twothirds $(2 / 3) \mathrm{PH}$ is a well-validated experimental model of liver regeneration that has been extensively used to study the underlying molecular and cellular mechanisms [8-12].

Growth factors such as TGF $\alpha$, EGF, and HGF are highly expressed after $\mathrm{PH}$ and are thought to be important in regulating hepatocyte activation, proliferation, migration, and survival during liver regeneration [13-15]. Hepatocyte growth factor (HGF) is the major hepatocyte mitogen [16], and HGF is upregulated after PH. HGF initiates hepatocyte DNA synthesis and stimulates hepatocyte growth $[16,17]$. 
Overexpression of HGF also increases hepatocyte proliferation and accelerates liver regeneration after $\mathrm{PH}$ [18]. Mice lacking c-MET, the HGF receptor, show delayed liver regeneration after $\mathrm{PH}$, with hepatocytes showing S-phase entry defects [19].

$\mathrm{TNF} \alpha$ is an important regulator of the "priming phase" of liver regeneration, and blocking $\mathrm{TNF} \alpha$ signaling in rats prior to $\mathrm{PH}$ significantly reduces the proliferation of hepatocytes and nonparenchymal liver cells $[20,21]$. TNF $\alpha$, together with its downstream effector IL-6, initiates hepatocyte transition from G0 to G1 phase of the cell cycle [21-23]. TNF $\alpha$ also activates transcription factors like STAT3 and NF- $\kappa \mathrm{B}$, which in turn promote the expression of cell cycle regulator genes such as cyclin D [24, 25].

The EGF receptor (EGFR) also plays a vital role in liver regeneration, since liver regeneration is not impaired in mice lacking TGF $\alpha$ because other EGFR ligands compensate for the absence of TGF $\alpha[14,26]$. EGFR is expressed at high levels in the adult liver and regulates liver development, function, and regeneration [13]. Transgenic mice lacking EGFR have a higher mortality rate after $\mathrm{PH}$, with surviving mice showing increased hepatocyte proliferation due to low cyclin D1 expression. The EGFR pathway regulates hepatocyte proliferation and efficient liver regeneration after $\mathrm{PH}$ [27, 28].

Resina draconis (RD), a bright resin extracted from Dracaena cochinchinensis (Lour.) S. C. Chen, is a Chinese Herbal medicine with a well-established safety and bioactivity record $[29,30]$. RD contributes to skin repair and can promote the development of transplanted epidermis, enhance the capillary proliferation [31], and promote the growth of fetal rat skin fibroblasts [32]. It can also improve wound healing [33] and has been used for the treatment of skin diseases [34, 35]. Further, RD can facilitate blood circulation and improve platelet function $[36,37]$. RD has anti-inflammatory effects [38] and antitumor activities $[39,40]$. Of these multiple activities, RD strongly promotes tissue recovery after injury. However, the effects of RD on liver regeneration after extended hepatectomy have not been investigated. Here, we explored the effect and possible mechanisms of RD treatment on liver regeneration in $2 / 3$ $\mathrm{PH}$ mice. The involvement of HGF, TNF $\alpha$, and EGFR signaling in $\mathrm{RD}$-stimulated liver regeneration was also investigated.

\section{Materials and Methods}

2.1. Preparation of Drugs. Resina draconis powder (Xishuangbanna Rainforest Pharmaceutical Co., Ltd., Jinghong, China) was dispersed in $1 \%$ sodium carboxymethyl cellulose (Na-CMC) at $10 \mathrm{mg} / \mathrm{mL}, 20 \mathrm{mg} / \mathrm{mL}$, and $40 \mathrm{mg} / \mathrm{mL}$ before intragastric injection into mice.

2.2. Animals. One-hundred forty-four 6-8 week-old male C57BL/ 6 mice weighing between 20 and $25 \mathrm{~g}$ were used. Animals were divided into three groups $(n=8$ in each group): sham, vehicle $+2 / 3 \mathrm{PH}$, and $\mathrm{RD}+2 / 3 \mathrm{PH}$. The $\mathrm{RD}+2 / 3 \mathrm{PH}$ group received intragastric injections of $0.2 \mathrm{~mL}$
$\mathrm{RD}$ solution at doses of $0.1 \mathrm{~g} / \mathrm{kg}, 0.2 \mathrm{~g} / \mathrm{kg}$, or $0.4 \mathrm{~g} / \mathrm{kg}$ body weight once daily for 10 days after $2 / 3 \mathrm{PH}$ surgery. All experiments were conducted under the institutional guidelines of the Animal Ethics Committee, Kunming Medical University.

2.3. Surgical Procedure and Anesthesia. 2/3 $\mathrm{PH}$ was performed in the vehicle $+2 / 3 \mathrm{PH}$ and $\mathrm{RD}+2 / 3 \mathrm{PH}$ groups using a slight modification of the methods developed by Harkness [41, 42]. Briefly, after general anesthesia, the left lateral, left median, and right median lobes were resected. Laparotomy was performed in the sham group without ligation and $2 / 3 \mathrm{PH}$.

2.4. Liver Tissue Collection. On days 0, 2, 4, 6, 8, and 10 after $2 / 3 \mathrm{PH}$, animals in each group were weighed and sacrificed humanly, liver tissues were collected and weighed, and the index of liver to body weight (ILBW) recorded.

2.5. Serum Parameters. Peripheral blood was collected and centrifuged. Serum alanine transaminase (ALT), aspartate transaminase (AST), alkaline phosphatase (ALP), albumin (ALB), and total protein (TP) were measured in U/L with a serum multiple biochemical analyzer (Diamond Diagnostics Inc., Holliston, USA).

2.6. Western Blotting. Liver tissue proteins were prepared as previously described [43]. Western blotting was performed using antibodies targeting PCNA (Invitrogen, Thermo Fisher Scientific, Waltham, MA, USA), $\beta$-actin (Sigma Aldrich, St. Louis, MO, USA), HGF (Abcam, Cambridge, UK), EGFR (Abcam), and TNF- $\alpha$ (Abcam). Super Signal West Dura Extended Duration Substrate (Pierce, Thermo Fisher Scientific, Waltham, MA, USA) was used to visualize antibody-antigen complexes.

2.7. Data Analysis. Three-way ANOVA was applied to analyze BW, ILBW, TP, ALB, ALT, ALP, and AST using the factors $2 / 3 \mathrm{PH}$ operation, $\mathrm{RD}$ treatment, and time after injury. Tukey's post hoc tests were applied as appropriate. Student's $t$ test was used to analyze data between two groups. All values were expressed as mean \pm SEM, and a $p$ value $<0.05$ was considered statistically significant.

\section{Results}

3.1. Resina Draconis Treatment Promotes Liver Weight Recovery after $2 / 3 \mathrm{PH}$. To address the effect of RD on general mouse health after $\mathrm{PH}$, mouse body weights were monitored after $2 / 3 \mathrm{PH}$. The body weights of mice reduced on days 2 and 4 after $2 / 3 \mathrm{PH}$ followed by weight gain on day 6 . RD treatment at different doses induced faster and longerlasting weight gain than vehicle group over 10 days (Figure 1(a)).

The ILBW from days 2 to 10 was measured after $2 / 3 \mathrm{PH}$ to address the effect of RD on liver recovery. The ILBW was significantly higher on days 2, 4, 6, 8, and 10 in RD-treated 


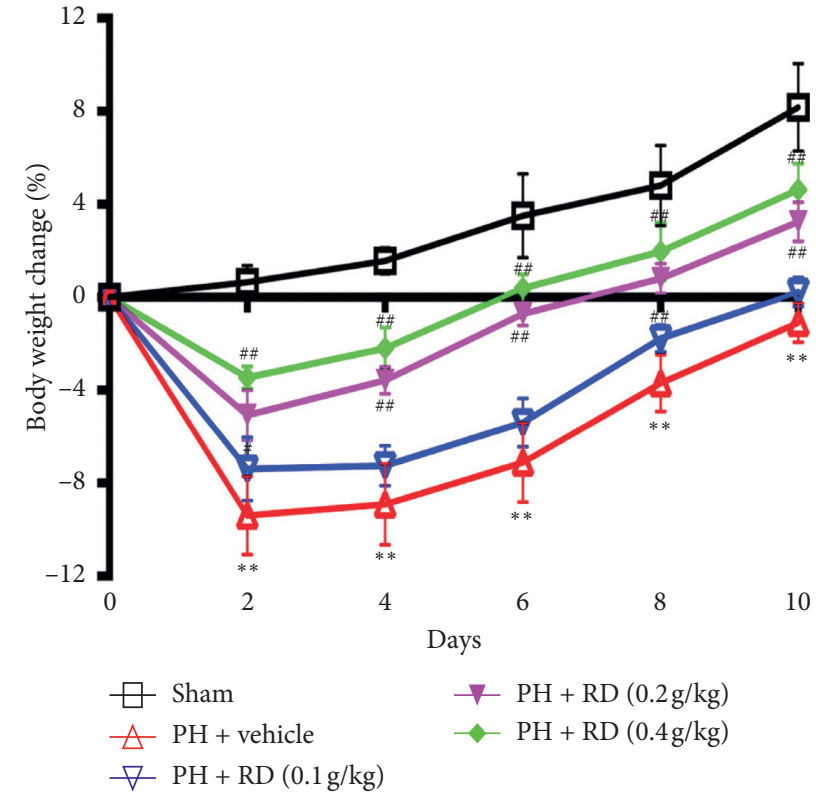

(a)

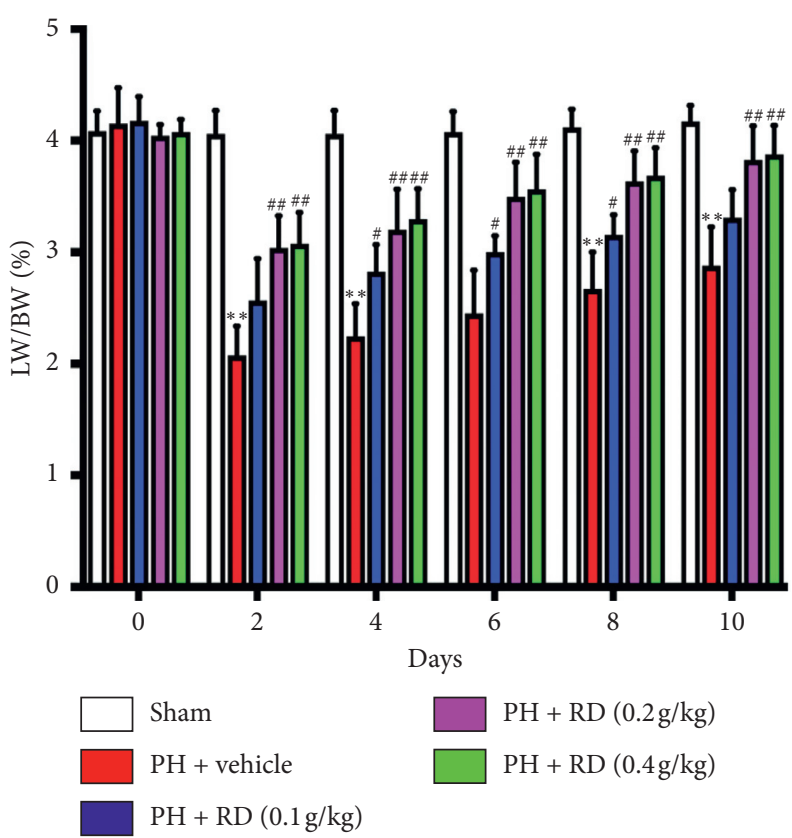

(b)

FIGURE 1: Resina draconis increases body weight and index of liver to body weight (ILBW) after 2/3 PH. (a) RD treatment at different doses increases body weight gain over time in mice receiving $2 / 3 \mathrm{PH}$. Results are represented as mean \pm SEM of percentage change in body weight versus original body weight before $2 / 3 \mathrm{PH}$. $n=8$ mice/time point. ${ }^{* *} p<0.01$, vehicle $+2 / 3 \mathrm{PH}$ group $v$ sham group; ${ }^{\# \#} p<0.01, \mathrm{RD}+2 / 3 \mathrm{PH}$ group $v s$ vehicle $+2 / 3 \mathrm{PH}$ group; ${ }^{\#} p<0.05$, RD vehicle + group $v s$ vehicle $+2 / 3 \mathrm{PH}$ group. (b) RD treatment increases ILBW over time in mice receiving $2 / 3 \mathrm{PH}$. Data are expressed as mean \pm SEM. $n=8$ mice/time point. ${ }^{* *} p<0.01$, vehicle $+2 / 3$ PH group $v s$ sham group; ${ }^{\# \#} p<0.01, \mathrm{RD}+2 / 3 \mathrm{PH}$ group $v s$ vehicle $+2 / 3 \mathrm{PH}$ group; ${ }^{\#} p<0.05, \mathrm{RD}+2 / 3 \mathrm{PH}$ group $v s$ vehicle $+2 / 3 \mathrm{PH}$ group.

mice versus vehicle controls (Figure $1(\mathrm{~b})$ ). Of the different $\mathrm{RD}$ concentrations tested, the $0.2 \mathrm{~g} / \mathrm{kg}$ and $0.4 \mathrm{~g} / \mathrm{kg}$ doses were most effective, with no significant difference between the $0.4 \mathrm{~g} / \mathrm{kg}$ treatment and $0.2 \mathrm{~g} / \mathrm{kg}$ treatment. Therefore, $0.2 \mathrm{~g} / \mathrm{kg}$ was used in subsequent experiments. These data indicate that $\mathrm{RD}$ treatment promotes liver recovery.

Resina draconis treatment prevents decreases in serum total protein (TP) and albumin (ALB) after $2 / 3 \mathrm{PH}$.

Given that $\mathrm{RD}$ treatment promoted liver regeneration, we further measured changes in serum total protein (TP) and albumin (ALB). TP and ALB levels were attenuated in both the $2 / 3 \mathrm{PH}$ group and the RD-treated $2 / 3 \mathrm{PH}$ group on days $2,4,6,8$, and 10 after PH. However, TP and ALB levels were significantly higher in the RD-treated $2 / 3 \mathrm{PH}$ group compared with the vehicle $+2 / 3$ PH group $(p<0.01)$ (Figures 2(a) and 2(b)). Furthermore, there was no unequivocal changes in the RD-treated $2 / 3 \mathrm{PH}$ group and the sham group on days $4,6,8$, and 10 after $\mathrm{PH}$.

3.2. Resina Draconis Treatment Restores Liver Function after 2/3 PH. Serum AST, ALT, and ALP levels are biomarkers of liver function. Serum AST and ALT levels significantly increased in both the $2 / 3 \mathrm{PH}$ and RD groups on days $2,4,6,8$, and 10 after $\mathrm{PH}$. However, the levels were significantly different in the $2 / 3 \mathrm{PH}$ group and the $\mathrm{RD}$ group $(p<0.01)$ (Figures 3(a) and 3(b)). ALP levels also significantly increased in the $2 / 3 \mathrm{PH}$ and $\mathrm{RD}$ groups on days 2, 4, 6 , and 8 after $\mathrm{PH}$. However, the levels were significantly different in the $2 / 3 \mathrm{PH}$ group and the $\mathrm{RD}$ group on days 2 and 4 $(p<0.01)$ (Figure 3(c)). Interestingly, the ALP and ALT levels in the RD group and vehicle group showed no significant difference on days 6,8 , and 10 after $\mathrm{PH}$. These results indicate that $\mathrm{RD}$ treatment not only enhances liver regeneration after $2 / 3 \mathrm{PH}$ but also restores $2 / 3 \mathrm{PH}$-induced loss of liver function as measured by liver function biomarkers.

3.3. Resina Draconis Treatment Enhances Hepatocyte Proliferation after $2 / 3 \mathrm{PH}$. Liver regeneration is closely related to hepatocyte proliferation. As RD promoted liver recovery, we hypothesized that RD enhanced hepatocyte proliferation. To address this hypothesis, we compared proliferating cell nuclear antigen (PCNA) levels in liver tissues between the different groups. PCNA expression was significantly higher on days 2, 4, and 6 in the $\mathrm{RD}$-treated group compared with the $2 / 3 \mathrm{PH}$ group (Figures $4(\mathrm{a}$ ) and $4(\mathrm{~b})$ ), with no observable change in PCNA expressed observed in the sham group.

3.4. Resina Draconis Treatment Induces HGF and Increases EGFR and TNF $\alpha$ after $2 / 3$ PH. HGF, EGFR, and TNF $\alpha$ are important growth factors that stimulate hepatocyte mitogenesis in liver regeneration $[44,45]$. To explore the possible mechanism by which RD promotes liver regeneration after 2/3 PH, HGF, EGFR, and TNF $\alpha$ expressions were measured in liver tissue by western blotting. In the vehicle $+2 / 3 \mathrm{PH}$ group and $\mathrm{RD}+2 / 3$ vehicle group, $\mathrm{HGF}$, EGFR, and TNF $\alpha$ increased significantly on day 2 after $2 / 3$ 

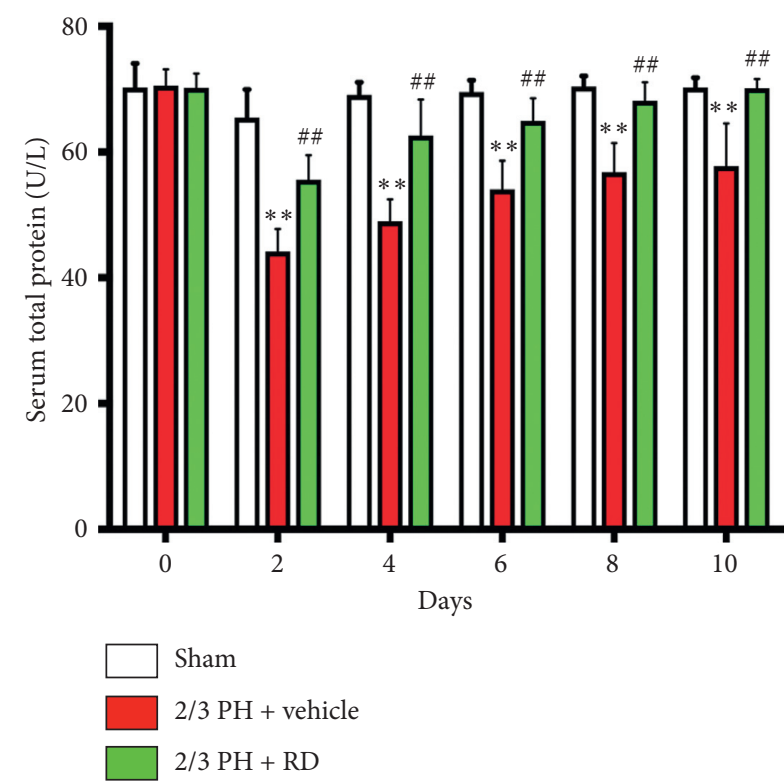

(a)
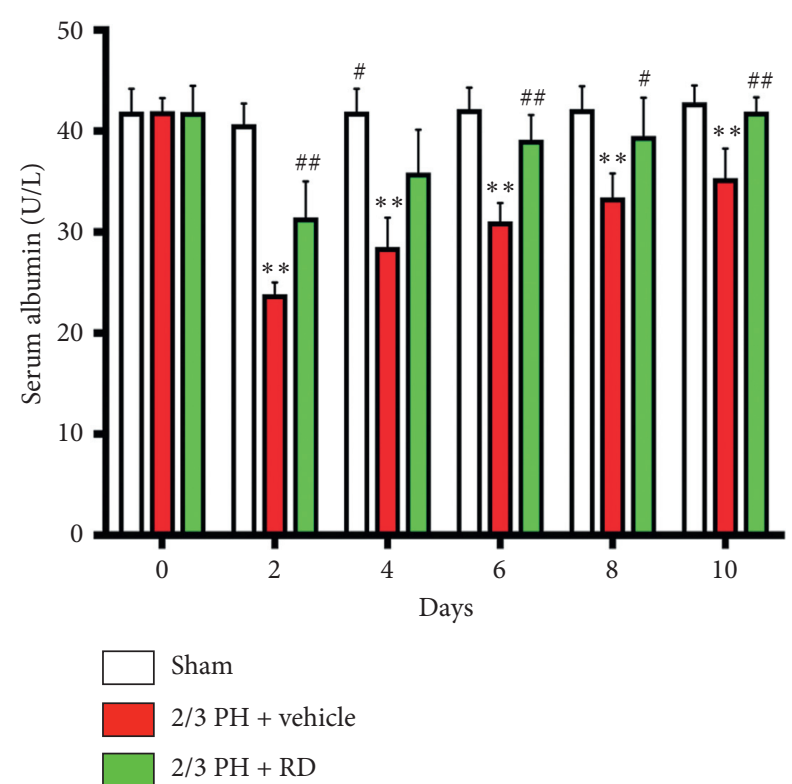

(b)

FIgURE 2: Resina draconis treatment prevents loss of serum TP and ALB after 2/3 PH. (a) RD treatment increases serum TP over time in mice receiving $2 / 3 \mathrm{PH}$. Results are represented as mean \pm SEM. $n=8$ mice/time point. ${ }^{* *} p<0.01$, vehicle $+2 / 3 \mathrm{PH}$ group vs sham group; \#\# $p<0.01, \mathrm{RD}+2 / 3 \mathrm{PH}$ group $v s$ vehicle $+2 / 3 \mathrm{PH}$ group. (b) RD treatment increases serum ALB over time in mice receiving $2 / 3 \mathrm{PH}$. Data are expressed as mean \pm SEM. $n=8$ mice/time point. ${ }^{* *} p<0.01$, vehicle $+2 / 3 \mathrm{PH}$ group $v s$ sham group; ${ }^{\# \#} p<0.01, \mathrm{RD}+2 / 3 \mathrm{PH}$ group $v s$ vehicle $+2 / 3 \mathrm{PH}$ group; ${ }^{\#} p<0.05$, RD group $v s 2 / 3 \mathrm{PH}$ group.
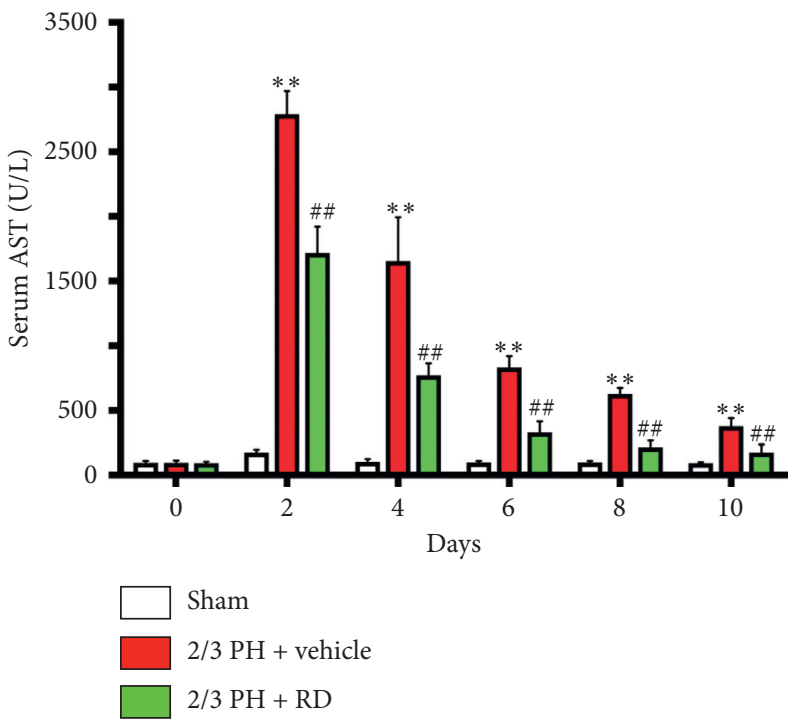

(a)
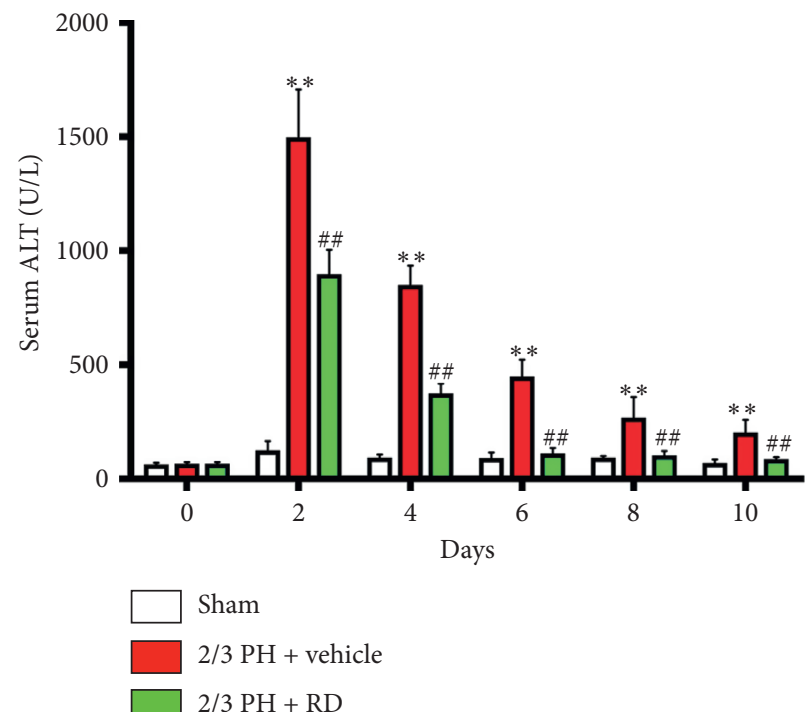

(b)

Figure 3: Continued. 


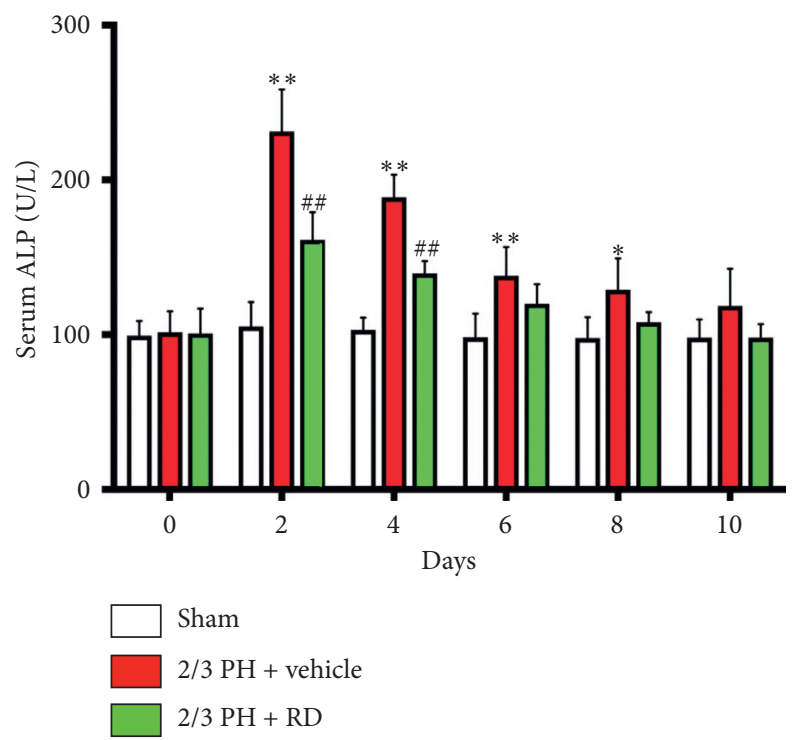

(c)

FIgURE 3: Resina draconis treatment prevents loss of liver function after 2/3 PH. (a) Serum AST levels were significantly increased in both the $2 / 3 \mathrm{PH}$ group and the RD group on days $2,4,6,8$, and 10 following $2 / 3 \mathrm{PH}$. Results are represented as mean $\pm \mathrm{SEM}$. $n=8$ mice/time point. ${ }^{* *} p<0.01$, vehicle $+2 / 3 \mathrm{PH}$ group $v s$ sham group; ${ }^{\# \#} p<0.01, \mathrm{RD}+2 / 3 \mathrm{PH}$ group $v s$ vehicle $+2 / 3 \mathrm{PH}$ group. (b) Serum ALT levels were significantly increased in both the $2 / 3 \mathrm{PH}$ group and the RD group on days $2,4,6,8$, and 10 following $2 / 3 \mathrm{PH}$. Results are represented as mean \pm SEM. $n=8$ mice/time point. ${ }^{* *} p<0.01$, vehicle $+2 / 3 \mathrm{PH}$ group $v s$ sham group; ${ }^{\# \#} p<0.01, \mathrm{RD}+\mathrm{PH}$ group $v s$ vehicle $+2 / 3 \mathrm{PH}$ group. (c) Serum ALP levels were significantly increased in both the $2 / 3 \mathrm{PH}$ group and the RD group on day 2, 4, 6, and 8 following $2 / 3 \mathrm{PH}$. Results are represented as mean \pm SEM. $n=8$ mice/time point. ${ }^{* *} p<0.01$, vehicle $+2 / 3 \mathrm{PH}$ group $v s$ sham group; ${ }^{*} p<0.05$, vehicle $+2 / 3 \mathrm{PH}$ group $v s$ sham group; ${ }^{\#} p<0.01, \mathrm{RD}+2 / 3 \mathrm{PH}$ group $v s$ vehicle $+2 / 3 \mathrm{PH}$ group.
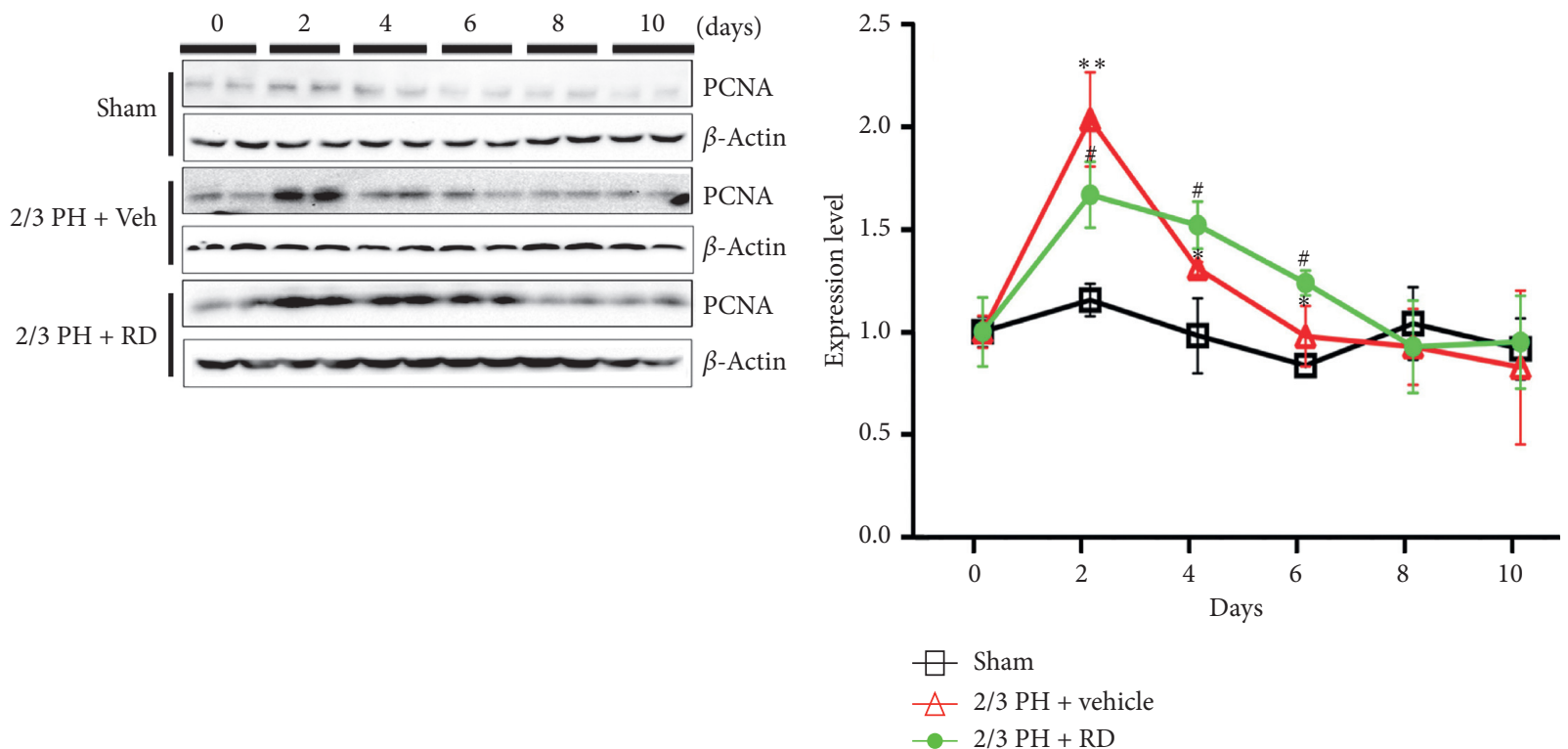

(a)

(b)

Figure 4: Resina draconis treatment enhances hepatocyte proliferation after 2/3 PH. (a). Representative western blotting analysis of PCNA protein in mouse livers after $2 / 3 \mathrm{PH}$ and sham operation. RD treatment increases PCNA expression after $2 / 3 \mathrm{PH}$. (b). Quantification of PCNA normalized to $\beta$-actin. Data are expressed as mean \pm SEM. $n=5 .{ }^{* *} p<0.01,2 / 3 \mathrm{PH}$ group $v s$ sham group; ${ }^{*} p<0.05,2 / 3 \mathrm{PH}$ group $v s$ sham group; ${ }^{\#} p<0.01, \mathrm{RD}+2 / 3 \mathrm{PH}$ group $v s$ vehicle $+2 / 3 \mathrm{PH}$ group; ${ }^{\#} p<0.05, \mathrm{RD}+2 / 3 \mathrm{PH}$ group $v s$ vehicle $+2 / 3 \mathrm{PH}$ group. 

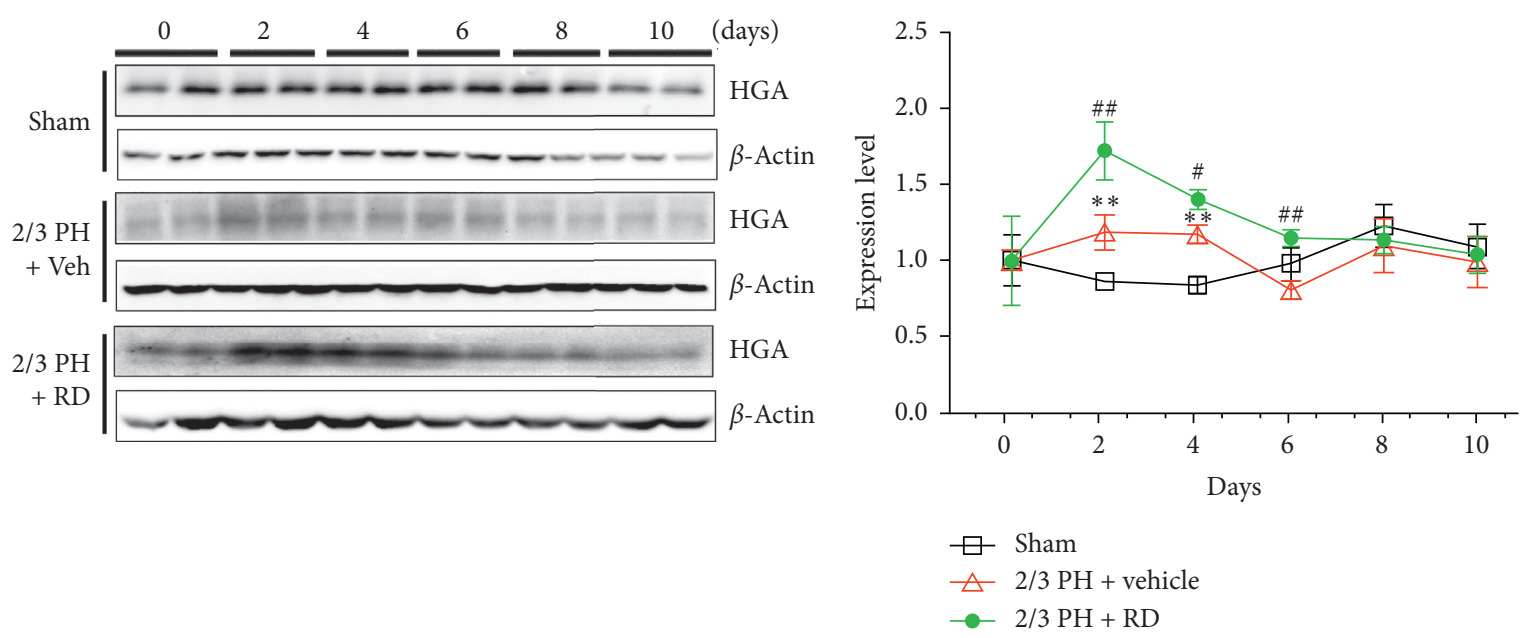

(a)
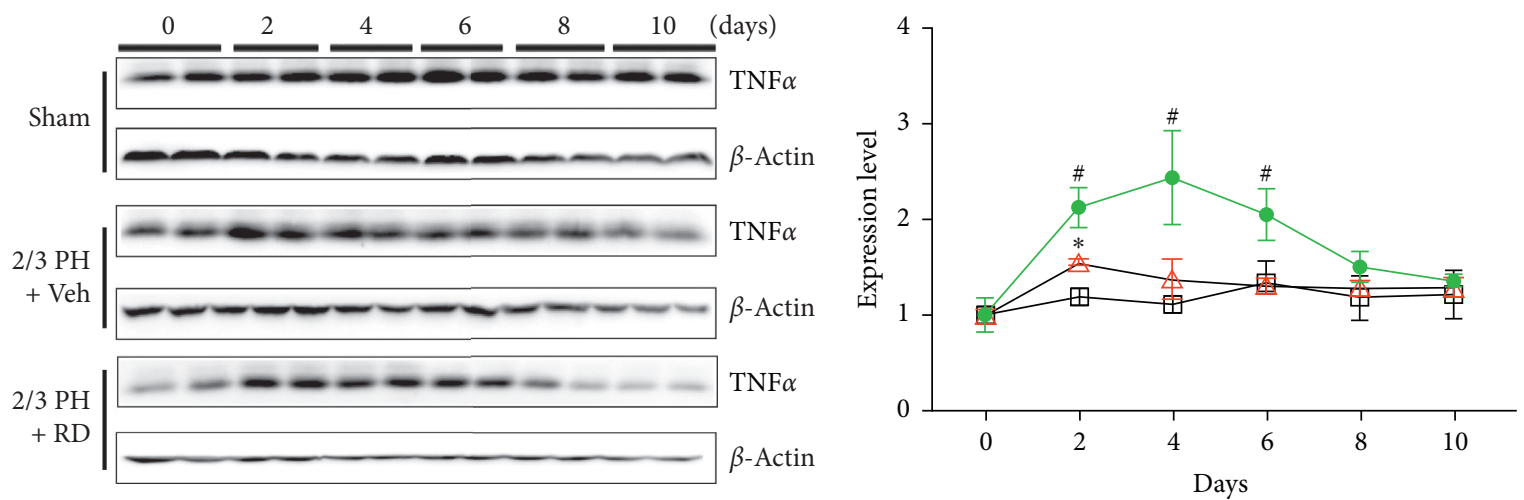

$\square$ Sham

$\triangle 2 / 3 \mathrm{PH}+$ vehicle

$\longrightarrow 2 / 3 \mathrm{PH}+\mathrm{RD}$

(c)
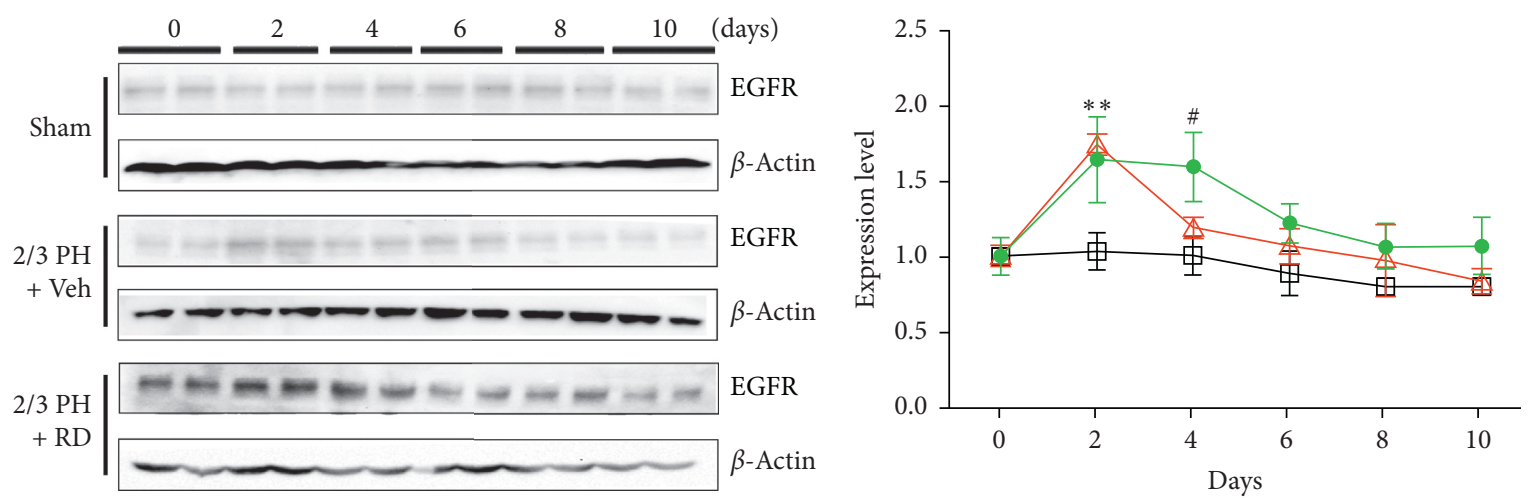

$\square$ Sham

$\triangle 2 / 3 \mathrm{PH}+$ vehicle

$\rightarrow 2 / 3 \mathrm{PH}+\mathrm{RD}$

(e)

(f)

Figure 5: Resina draconis treatment affects HGF, EGFR, and TNF $\alpha$ levels after 2/3 PH. (a) and (b). Representative western blotting analysis of HGF protein in mouse livers after 2/3 PH and sham operations. RD treatment increases the HGF expression after 2/3 PH. Quantifications were normalized to $\beta$-actin. (c) and (d). Representative western blotting analysis of HGF protein in mouse livers after $2 / 3 \mathrm{PH}$ and sham operations. RD treatment increases TNF $\alpha$ expression after 2/3 PH. Quantifications were normalized to $\beta$-actin. (e) and (f). Representative western blotting analysis of EGFR protein in mouse livers after $2 / 3 \mathrm{PH}$ and sham operations. RD treatment increases the TNF $\alpha$ expression after $2 / 3 \mathrm{PH}$. Quantifications were normalized to $\beta$-actin. All the data are expressed as mean \pm SEM. $n=5 .{ }^{* *} p<0.01$, vehicle $+2 / 3 \mathrm{PH}$ group $v s$ sham group; ${ }^{*} p<0.05$, vehicle $+2 / 3 \mathrm{PH}$ group $v$ sham group; ${ }^{\#} p<0.05, \mathrm{RD}+2 / 3 \mathrm{PH}$ group vs $2 / 3 \mathrm{PH}$ group. 
$\mathrm{PH}$ and decreased progressively to preoperative levels by the end of the observation period. However, the levels of HGF (Figures 5(a) and 5(b)), EGFR (Figures 5(c) and 5(d)), and TNF $\alpha$ (Figures 5(e) and 5(f)) were significantly higher on day 2 and day 4 after $2 / 3 \mathrm{PH}(p<0.05)$ in the $\mathrm{RD}+2 / 3 \mathrm{PH}$ group than in vehicle $+2 / 3 \mathrm{PH}$ group and sham group. Further, trends in these increases continued to day 6 and day 8 .

\section{Discussion}

Despite clinical advances, liver diseases remain a severe health problem worldwide. Liver resection is the primary treatment modality for liver cancer and other serious liver diseases [46-52]. Liver regeneration plays a vital role in recovery after resection. Acute liver failure after hepatectomy is a main cause of postoperative mortality and morbidity [53-57]. How to protect against postoperative liver injury and promote liver regeneration remains an urgent unmet clinical need. $\mathrm{RD}$ has been used for many years to promote wound healing $[32,58]$ and as anticoagulant [59-61]. Several studies have shown that RD has hemostatic and anti-inflammatory properties and promotes blood circulation and skin repair [62-65]. Here, for the first time, we provide evidence that $\mathrm{RD}$ treatment is beneficial to liver regeneration and protects against liver injury after $2 / 3 \mathrm{PH}$. Furthermore, RD-stimulated HGF, EGFR, and TNF $\alpha$ signaling during liver regeneration after $2 / 3 \mathrm{PH}$. These findings offer a new avenue for protecting against postoperative liver failure and controlling liver regeneration after liver resection.

The exact mechanisms of liver regeneration after $2 / 3$ $\mathrm{PH}$ are complicated and have not been fully defined, although a number of growth factors are implicated in the process. HGF, EGFR, and TNF $\alpha$ are potential initiators of liver regeneration and increase immediately and are maintained after $2 / 3 \mathrm{PH}$. Here, we found that the expressions of HGF, EGFR, and TNF $\alpha$ increased significantly after $2 / 3 \mathrm{PH}$ compared with those of controls on days 2 and 4 after $2 / 3 \mathrm{PH}$ and were significantly higher in the $\mathrm{RD}$-treated 2/3 $\mathrm{PH}$ group than in the vehicle-treated 2/ $3 \mathrm{PH}$ group. Expression of these growth factors is a key step to initial hepatocyte proliferation and improving liver regeneration and functional recovery. The promitogenic effect of RD-induced expression of these factors was further supported by the observation of higher expression of proliferating cell nuclear antigen (PCNA) in RDtreated mice.

Serum AST and ALT liver function biomarkers are inversely related to the severity of liver damage [66-68]. We found that both ALT and AST levels were significantly higher in the $2 / 3 \mathrm{PH}$ group mice than in the sham group mice on day 2 and day 4 after $2 / 3 \mathrm{PH}$ and that RD treatment reversed these changes. TB and ALB are markers of liver synthetic function [69-72]. Our study revealed that TB and ALB levels were higher in the RDtreated 2/3 PH group on day 2 and day 4 after the operation than in vehicle-treated $2 / 3 \mathrm{PH}$. Interestingly, RDtreated not only reduced the liver function biomarker levels compared with the vehicle-treated $\mathrm{PH}$ group but also it recovered levels to sham over the study period. These results strongly indicate that RD treatment protects against acute liver damage and stimulates liver regeneration after $2 / 3 \mathrm{PH}$.

Taken together, our results confirm that intragastric injection of RD after 2/3 $\mathrm{PH}$ prevents acute liver failure and promotes liver regeneration. HGF, EGFR, and TNF $\alpha$ are involved in this process. These results indicate that $\mathrm{RD}$ may be useful in the treatment of acute liver injury.

\section{Abbreviations \\ RD: Resina draconis \\ PH: Partial hepatectomy \\ ILBW: Index of liver to body weight \\ PCNA: Proliferating cell nuclear antigen \\ AST: Aspartate transaminase \\ ALT: Alanine transaminase \\ TP: Total protein \\ ALB: Albumin \\ HGF: Hepatocyte growth factor \\ TNF $\alpha$ : Tumor necrosis factor \\ EGF: Epidermal growth factor \\ LDLT: Living donor liver transplantation \\ NF- $\kappa$ B: Nuclear factor kappa B.}

\section{Data Availability}

The data used to support the study findings are available within the article.

\section{Conflicts of Interest}

The authors declare that there are no conflicts of interest.

\section{Authors' Contributions}

Zhi-yong He, Kai-han Lou, and Jia-hui Zhao performed the research; Wei-yan $\mathrm{Hu}$ and Rong-ping Zhang designed the research; Wei-yan $\mathrm{Hu}$ and Zhi-yong $\mathrm{He}$ analyzed the data and wrote the paper; Ming Zhang revised the manuscript; Lang-chun Zhang, Ju $\mathrm{Li}$ and Hao-fei Yu prepared the figures.

\section{Acknowledgments}

This work was supported by grants from the National Natural Science Foundation of China (81960666 and 81860254, W.Y.H.), the National Natural Science Foundation of Yunnan (2019FA033, R.P.Z.), the Program for Innovative Research Team in Science and Technology in Yunnan Province (2019HC008), and Yunnan Provincial Science and Technology Department (202005AF150043). The support provided by Yunnan Key Laboratory of Stem Cell and Regenerative Medicine (M. Z. and W.Y.H.) is also appreciated. 


\section{Supplementary Materials}

This section includes graphical abstract. (Supplementary Materials)

\section{References}

[1] J. A. Cienfuegos, F. Rotellar, J. Baixauli et al., "Liver regeneration-the best kept secret: a model of tissue injury response," Revista Española de Enfermedades Digestivas, vol. 106, no. 3, pp. 171-194, 2014.

[2] N. Fausto, J. S. Campbell, and K. J. Riehle, "Liver regeneration," Hepatology, vol. 43, no. 2, pp. S45-S53, 2000.

[3] J. M. Gentile, L. Avila, and J. T. Grace, "Liver regeneration. old and new concepts," The American Journal of Surgery, vol. 120, no. 1, pp. 2-6, 1970

[4] K. J. Riehle, Y. Y. Dan, J. S. Campbell, and N. Fausto, "New concepts in liver regeneration," Journal of Gastroenterology and Hepatology, vol. 26, no. 1, pp. 203-212, 2011.

[5] A. Cieslar-Pobuda and E. Wiechec, "Research on liver regeneration as an answer to the shortage of donors for liver transplantation," Hepatology Research, vol. 44, no. 9, pp. 944-946, 2014.

[6] K. M. Olthoff, J. C. Emond, T. H. Shearon et al., "Liver regeneration after living donor transplantation: adult-to-adult living donor liver transplantation cohort study," Liver Transplantation, vol. 21, no. 1, pp. 79-88, 2015.

[7] D. Pagano, M. Spada, V. Parikh et al., "Liver regeneration after liver resection: clinical aspects and correlation with infective complications," World Journal of Gastroenterology, vol. 20, no. 22, pp. 6953-6960, 2014.

[8] N. L. Bucher and G. C. Weir, "Insulin, glucagon, liver regeneration, and dna synthesis," Metabolism, vol. 25, no. 11, pp. 1423-1425, 1976.

[9] A. N. Kandilis, J. Koskinas, I. Vlachos et al., "Liver regeneration: immunohistochemichal study of intrinsic hepatic innervation after partial hepatectomy in rats," BMC Gastroenterology, vol. 14, no. 1, p. 202, 2014.

[10] K. N. Tzirogiannis, K. T. Kourentzi, S. Zyga et al., "Effect of 5HT 7 receptor blockade on liver regeneration after $60-70 \%$ partial hepatectomy," BMC Gastroenterology, vol. 14, no. 1, p. 201, 2014.

[11] J. H. Wolf, T. R. Bhatti, S. Fouraschen et al., "Heat shock protein 70 is required for optimal liver regeneration after partial hepatectomy in mice," Liver Transplantation, vol. 20, no. 3, pp. 376-385, 2014.

[12] T. Wu, J. Huang, S. Wu et al., "Deficiency of periostin impairs liver regeneration in mice after partial hepatectomy," Matrix Biology, vol. 66, pp. 81-92, 2018.

[13] U. Marti, S. J. Burwen, and A. L. Jones, "Biological effects of epidermal growth factor, with emphasis on the gastrointestinal tract and liver: an update," Hepatology, vol. 9, no. 1, pp. 126-138, 1989.

[14] G. K. Michalopoulos, "Advances in liver regeneration," Expert Review of Gastroenterology \& Hepatology, vol. 8, no. 8, pp. 897-907, 2014.

[15] G. K. Michalopoulos and Z. Khan, "Liver regeneration, growth factors, and amphiregulin," Gastroenterology, vol. 128, no. 2, pp. 503-506, 2005.

[16] R. Imamura and K. Matsumoto, "Hepatocyte growth factor in physiology and infectious diseases," Cytokine, vol. 98, pp. 97-106, 2017.

[17] C. G. Huh, V. M. Factor, A. Sanchez et al., "Hepatocyte growth factor/c-met signaling pathway is required for efficient liver regeneration and repair," Proceedings of the National Academy of Sciences, vol. 101, no. 13, pp. 44774482, 2004

[18] X. F. Cao, S. Z. Jin, L. Sun et al., "Therapeutic effects of hepatocyte growth factor-overexpressing dental pulp stem cells on liver cirrhosis in a rat model," Scientific Reports, vol. 7, no. 1, Article ID 15812, 2017.

[19] S. Paranjpe, W. C. Bowen, A. W. Bell et al., "Cell cycle effects resulting from inhibition of hepatocyte growth factor and its receptor c-Met in regenerating rat livers by RNA interference," Hepatology, vol. 45, no. 6, pp. 1471-1477, 2017.

[20] G. M. Argast, J. S. Campbell, J. T. Brooling, and N. Fausto, "Epidermal growth factor receptor transactivation mediates tumor necrosis factor-induced hepatocyte replication," Journal of Biological Chemistry, vol. 279, no. 33, pp. 3453034536, 2004.

[21] J. Sun, Z. Yang, X. C. Shi et al., "G0S2a1 (G0/G1 switch gene 2a1) is downregulated by TNF-alpha in grass carp (Ctenopharyngodon idellus) hepatocytes through PPARalpha inhibition," Gene, vol. 641, pp. 1-7, 2018.

[22] D. E. Cressman, L. E. Greenbaum, R. A. DeAngelis et al., "Liver failure and defective hepatocyte regeneration in interleukin-6-deficient mice," Science, vol. 274, no. 5291, pp. 1379-1383, 1996.

[23] G. M. Ledda-Columbano, M. Curto, R. Piga et al., "In vivo hepatocyte proliferation is inducible through a TNF and IL-6independent pathway," Oncogene, vol. 17, no. 8, pp. 1039-1044, 1998.

[24] W. Li, X. Liang, C. Kellendonk, V. Poli, and R. Taub, "STAT3 contributes to the mitogenic response of hepatocytes during liver regeneration," Journal of Biological Chemistry, vol. 277, no. 32, pp. 28411-28417, 2002.

[25] Y. Yamada, I. Kirillova, J. J. Peschon, and N. Fausto, "Initiation of liver growth by tumor necrosis factor: deficient liver regeneration in mice lacking type I tumor necrosis factor receptor," Proceedings of the National Academy of Sciences, vol. 94, no. 4, pp. 1441-1446, 1997.

[26] G. K. Michalopoulos, "Principles of liver regeneration and growth homeostasis," Comprehensive Physiology, vol. 3, no. 1, pp. 485-513, 2013.

[27] B. Bhushan, H. Chavan, P. Borude et al., "Dual role of epidermal growth factor receptor in liver injury and regeneration after acetaminophen overdose in mice," Toxicological Sciences, vol. 155, no. 2, pp. 363-378, 2017.

[28] H. Zhang, J. H. Shi, H. Jiang et al., "ZBTB20 regulates EGFR expression and hepatocyte proliferation in mouse liver regeneration," Cell Death \& Disease, vol. 9, no. 5, p. 462, 2018.

[29] M. Bruck, "Dragon's blood. A glance into the history of pharmacognosy," "Bulletin de la Société des Sciences Médicales du Grand Duché de Luxembourg, vol. 1, pp. 96101, 1999.

[30] L. L. Fan, P. F. Tu, J. X. He, H. B. Chen, and S. Q. Cai, "Microscopical study of original plant of Chinese drug "dragon's blood" dracaena cochinchinensis and distribution and constituents detection of its resin," Zhongguo Zhong Yao Za Zhi, vol. 33, no. 10, pp. 1112-1117, 2008.

[31] A. J. Liu, Y. H. Zhu, and Z. X. Zhao, "Effect of resina draconis is in the repair of skin defect treated with tissue engineering skin," Guangzhou University of Chinese Medicine, vol. 26, pp. 260-262, 2009.

[32] A. J. Liu, J. T. Huang, and L. Q. Zhang, "Growth of fetal mouse skin filbrobasts stimulated by effect locus of resina draconis," Journal of Sichuan Traditional Chinese Medicine, vol. 28, pp. 46-48, 2014. 
[33] F. Namjoyan, F. Kiashi, Z. B. Moosavi, F. Saffari, and B. S. Makhmalzadeh, "Efficacy of dragon's blood cream on wound healing: a randomized, double-blind, placebo-controlled clinical trial," Journal of Traditional and Complementary Medicine, vol. 6, pp. 37-40, 2016.

[34] J. S. Li, "Application of dragon's blood in treating surface wounds and burns," Journal of Harbin Medical University, vol. 21, p. 70, 2001.

[35] X. P. Lu, "20 cases of alopecia areata treatment efficacy blood capsules," Jilin Medical Journal, vol. 30, p. 1391, 2009.

[36] X. Nian, J. L. Yu, and L. Yan, "Dragon's blood extract has antithrombotic properties, affecting platelet aggregation functions and anticoagulation activities," Journal of Ethnopharmacology, vol. 135, pp. 510-514, 2011.

[37] J. Sun, J.-N. Liu, and B. Fan, "Phenolic constituents, pharmacological activities, quality control, and metabolism of dracaena species: a review," Journal of Ethnopharmacology, vol. 244, 2019.

[38] Y. D. Zhu, P. Zhang, and H. P. Yu, "Anti-helicobacter pylori and thrombin inhibitory components from Chinese dragon's blood Dracaena cochinchinensis," Journal of Natural Products, vol. 70, pp. 1570-1577, 2007.

[39] F. Wen, X. Zhao, Y. Zhao, Z. Lu, and Q. Guo, “The anticancer effects of resina draconis extract on cholangiocarcinoma," Tumour Biology, vol. 37, no. 11, pp. 15203-15210, 2016.

[40] Y.-N. Zhao, A.-L. Yang, D.-R. Pang et al., "Anti-tumor activity of HIS-4, a biflavonoid from resina draconis, on human hepatoma HepG2 and SK-HEP-1 cells," Zhongguo Zhong Yao Za Zhi, vol. 44, no. 7, pp. 1442-1449, 2019.

[41] R. D. Harkness, "Changes in the liver of the rat after partial hepatectomy," The Journal of Physiology, vol. 117, no. 3, pp. 267-277, 1952.

[42] R. D. Harkness, "Collagen in regenerating liver of the rat," The Journal of Physiology, vol. 117, no. 3, pp. 257-266, 1952.

[43] K. Lou, M. Yang, E. Duan et al., "Rosmarinic acid stimulates liver regeneration through the mTOR pathway," Phytomedicine, vol. 23, no. 13, pp. 1574-1582, 2016.

[44] A. Blindenbacher, X. Wang, I. Langer et al., "Interleukin 6 is important for survival after partial hepatectomy in mice," Hepatology, vol. 38, no. 3, pp. 674-682, 2003.

[45] I. Quetier, N. Brezillon, M. Duriez et al., "Hepatitis B virus $\mathrm{HBx}$ protein impairs liver regeneration through enhanced expression of IL-6 in transgenic mice," The Journal of Physiology, vol. 59, no. 2, pp. 285-291, 2013.

[46] B. Aussilhou, G. Doufle, C. Hubert et al., "Extended liver resection for polycystic liver disease can challenge liver transplantation," Annals of Surgery, vol. 252, no. 5, pp. 735-743, 2010.

[47] T. Belda, E. M. Montalva, R. Lopez-Andujar et al., "Role of resection surgery in breast cancer liver metastases: experience over the last 10 years in a reference hospital," Cirugía Española, vol. 88, no. 3, pp. 167-173, 2010.

[48] A. Bueno, F. Rotellar, A. Benito et al., "Laparoscopic limited liver resection decreases morbidity irrespective of the hepatic segment resected," $H P B$, vol. 16, no. 4, pp. 320-326, 2014.

[49] D. Ehrl, K. Rothaug, D. Hempel, and H. G. Rau, "Importance of liver resection in case of hepatic breast cancer metastases," Hepato-Gastroenterology, vol. 60, no. 128, pp. 2026-2033, 2013.

[50] C. Marin, R. Robles, M. Fuster, and P. Parrilla, "Laparoscopic liver resection of a desmoplastic nested spindle cell tumor of the liver," The American Surgeon, vol. 76, no. 9, pp. E184E185, 2010.
[51] J. P. McAteer, A. B. Goldin, P. J. Healey, and K. W. Gow, "Surgical treatment of primary liver tumors in children: outcomes analysis of resection and transplantation in the SEER database," Pediatric Transplantation, vol. 17, no. 8, pp. 744-750, 2013.

[52] L. Vigano, L. Capussotti, G. De Rosa et al., "Liver resection for colorectal metastases after chemotherapy: impact of chemotherapy-related liver injuries, pathological tumor response, and micrometastases on long-term survival," Ann Surg, vol. 258, no. 5, pp. 731-740, 2013.

[53] I. Colle, X. Verhelst, A. Vanlander et al., "Pathophysiology and management of post resection liver failure," Acta Chirurgica Belgica, vol. 113, no. 3, pp. 155-161, 2013.

[54] T. Hirashita, M. Ohta, Y. Iwashita et al., "Risk factors of liver failure after right-sided hepatectomy," The American Journal of Surgery, vol. 206, no. 3, pp. 374-379, 2013.

[55] K. J. Roberts, K. G. Bharathy, and J. P. Lodge, "Kinetics of liver function tests after a hepatectomy for colorectal liver metastases predict post-operative liver failure as defined by the international study group for liver surgery," $H P B$, vol. 15, no. 5, pp. 345-351, 2013.

[56] E. Vibert, G. Pittau, M. Gelli et al., "Actual incidence and longterm consequences of posthepatectomy liver failure after hepatectomy for colorectal liver metastases," Surgery, vol. 155, no. 1, pp. 94-105, 2014.

[57] D. C. Yu, W. B. Chen, C. P. Jiang, and Y. T. Ding, "Risk assessment in patients undergoing liver resection," Нерatobiliary \& Pancreatic Diseases International, vol. 12, no. 5, pp. 473-479, 2013.

[58] L. Pieters, T. De Bruyne, B. Van Poel et al., "In vivo wound healing activity of dragon's blood (croton spp.), a traditional south American drug, and its constituents," Phytomedicine, vol. 2, no. 1, pp. 17-22, 1995.

[59] D. Gupta, B. Bleakley, and R. K. Gupta, "Dragon's blood: botany, chemistry and therapeutic uses," Journal of Ethnopharmacology, vol. 115, no. 3, pp. 361-380, 2008.

[60] L. Pieters, T. De Bruyne, M. Claeys et al., "Isolation of a dihydrobenzofuran lignan from south American dragon's blood (croton spp.) as an inhibitor of cell proliferation," Journal of Natural Products, vol. 56, no. 6, pp. 899-906, 1993.

[61] N. Xin, Y. J. Li, X. Li et al., "Dragon's blood may have radioprotective effects in radiation-induced rat brain injury," Radiation Research, vol. 178, no. 1, pp. 75-85, 2012.

[62] J. Y. Fan, T. Yi, C. M. Sze-To et al., "A systematic review of the botanical, phytochemical and pharmacological profile of Dracaena cochinchinensis, a plant source of the ethnomedicine "dragon's blood"," Molecules, vol. 19, no. 7, pp. 10650-10669, 2014.

[63] N. Li, Z. Ma, M. Li, Y. Xing, and Y. Hou, "Natural potential therapeutic agents of neurodegenerative diseases from the traditional herbal medicine Chinese dragon's blood," Journal of Ethnopharmacology, vol. 152, no. 3, pp. 508-521, 2014.

[64] Y. S. Li, J. X. Wang, M. M. Jia et al., “Dragon's blood inhibits chronic inflammatory and neuropathic pain responses by blocking the synthesis and release of substance P in rats," Journal of Pharmacological Sciences, vol. 118, no. 1, pp. 43-54, 2012.

[65] V. S. Rao, L. A. Gurgel, R. C. Lima-Junior et al., “Dragon's blood from Croton urucurana (baill.) attenuates visceral nociception in mice," Journal of Ethnopharmacology, vol. 113, no. 2, pp. 357-360, 2007.

[66] B. Avci, A. Bahadir, O. K. Tuncel, and B. Bilgici, "Influence of alpha-tocopherol and alpha-lipoic acid on bisphenol-A- 
induced oxidative damage in liver and ovarian tissue of rats," Toxicology and Industrial Health, vol. 32, 2016.

[67] S. Gurgen, A. Yucel, A. Karakus et al., "Usage of whey protein may cause liver damage via inflammatory and apoptotic responses," Human \& Experimental Toxicology, vol. 34, 2015.

[68] G. Henrique Da Silva, P. P. Barros, G. M. Silva Goncalves, and M. A. Landi, "Hepatoprotective effect of Lycopodium clavatum $30 \mathrm{CH}$ on experimental model of paracetamol-induced liver damage in rats," Homeopathy, vol. 104, no. 1, pp. 29-35, 2015.

[69] S. A. Akuyam, O. K. Uchenna, A. Adamu et al., "Liver function tests profile in cancer patients on cytotoxic chemotherapy: a preliminary report," Nigerian Postgraduate Medical Journal, vol. 18, no. 1, pp. 34-33, 2011.

[70] J. X. Li, H. Wu, J. W. Huang, and Y. Zeng, "The influence on liver function after transcatheter arterial chemoembolization combined with percutaneous radiofrequency ablation in patients with hepatocellular carcinoma," Journal of the Formosan Medical Association, vol. 111, no. 9, pp. 510-515, 2012.

[71] Z. Wang, X. P. Chen, Z. Q. Liang et al., "Therapeutic effect of autologous bone marrow stem cell transplantation in the treatment of severe liver damage," Nan Fang Yi Ke Da Xue Xue Bao, vol. 30, no. 12, pp. 2762-2764, 2010.

[72] L. Zhu, Z. C. Yang, A. Li, and D. C. Cheng, "Protective effect of early enteral feeding on postburn impairment of liver function and its mechanism in rats," World Journal of Gastroenterology, vol. 6, no. 1, pp. 79-83, 2000. 